and Eurasian (smaller) basins. The Amerasian basin, in turn, is divided unequally by the Alpha ridge, a broad fractured structure with rugged topography and complex morphology; and the Eurasian basin is cut roughly in half by the Nansen ridge, a seismically active offset extension of the midAtlantic ridge. Significantly, the three ridges are almost parallel to each other. Less significantly, the Lomonosov ridge is unique in that its edge lies beneath the north geographical pole.

All the evidence suggests that the Nansen ridge began spreading about 40 million years ago and continues to do so at a rate of about $1.0 \mathrm{~cm}$ a year; it has a clear geographical relationship with the mid-Atlantic ridge, is associated with a well defined pattern of earthquake epicentres, and gives rise to typical linear magnetic anomalies (albeit with smaller than usual amplitudes). The Alpha ridge, on the other hand, is evidently inactive in terms of both seismicity and spreading, although it is associated with linear magnetic anomalies of high amplitude. This last observation led Vogt and Ostenso (J. Geophys. Res., 70, 4925; $1970)$ to propose that the Alpha ridge, though now dormant, is the site of ancient seafloor spreading. According to this plausible interpretation, spreading would have begun about 200 million years ago (possibly simultaneously with the opening of the North Atlantic) and ended about 40 million years ago when the activity transferred to the Nansen ridge. Dawes tends to be more cautious about this, drawing attention to Vogt and Ostenso's own admission that the Alpha ridge may represent "something entirely different".

But if the Alpha and Nansen ridges are essentially oceanic features, the Lomonosov ridge is thought to be of continental origin, although it lies in

\section{Democratic science}

THE multiauthor paper has become a commonplace and the multinational project has come into its own. But authors usually achieve a consensus before publishing and present a united if sometimes cautious front. The latest multinational attempt to resolve some of the thorny problems of mycobacterial taxomy (Meissner et al., J. gen. Microbiol., 83, 207; 1974), however, has resulted in a published majority report with six out of the twenty-two authors presenting their own dissident statement on one of the proposals. Perhaps this approach could be encouraged; it would certainly make for more interesting reading in most scientific papers. an anomalous geographical position. It is aseismic, has no linear magnetic anomalies associated with it and it is generally quiet magnetically-all of which suggests a scarcity of igneous rock. But this is negative evidence; and positive evidence in favour of a continental composition is more sparse. It is true that a seismic profile obtained by Ostenso (in Implications of Continental Drift to the Earth Sciences, Academic Press, 1973) indicates a smooth topography and a deep sedimentary structure; but again this relies for much of its effect on a comparison with known oceanic ridge structures. It is also true that positive, if indirect, evidence for the Lomonosov ridge's continental nature may be adduced from structures on the land adjacent to the Arctic Ocean, although, as Dawes points out with respect to the alignment of the ridge with geological features on Ellesmere Island, this support could prove to be ambiguous in the face of data suggesting that the ridge, although continental, originates elsewhere.

More positive evidence is thus urgently required-and has now been provided, within limits, by Lillestrand and Weber (J. Geophys. Res., 79, 3347; 1974). During the Second Canadian North Pole Expedition (1969) these workers measured the plumb line deflection in the vicinity of the Lomonosov ridge near the North Pole by comparing the paths of a drifting ice island station as measured astronomically and as determined by means of a Transit Satellite receiver. (The displacement between the two independently determined paths gives the plumb line defleotion almost directly.) The mean deflection at $89^{\circ} 40^{\prime} \mathrm{N}$, $77^{\circ} \mathrm{W}$ was found to be 9 arc s towards $34^{\circ} \mathrm{E}$, and the estimated deflection at the rotational north pole is $4-8$ arc $s$ in the direction $20-40^{\circ} \mathrm{E}$.

This is apparently the first time that the plumb line deflection at the North Pole has been determined; and so the result is of interest in itself. But it is also important in connection with the nature of the Lomonosov ridge, for Lillestrand and Weber go on to show that the measured deflection is in good agreement with the value predicted from a model constructed on the assumption that the ridge is a sedimentary structure underlain by a lower density continental crustal block. Moreover, several gravity measurements made in the area are consistent with the free air gravity anomaly computed from the same model. Of course, all gravity-based interpretations are ambiguous in that any data set can be accounted for by a large number of different structures. Within this limitation, however, the new result from the North Pole cannot but strengthen support for the view, first put forward by Heezen and Ewing (in Geology of the Arctic, University of Toronto Press, 1961) and later expanded by Wilson (Nature, 198, 929; 1963), that the Lomonosov ridge represents a section of the Siberian continental margin split off when the Nansen ridge became active beneath the edge of Eurasia.

\section{Diseases of skeletal muscle}

\section{from a Correspondent}

Much of the work of the Third International Congress on Muscle Diseases (Newcastle upon Tyne, September 15 to 20) dealt with the interaction between nerve and muscle. Dr. L. Guth (National Institutes of Health, Bethesda) opened the meeting with a review of trophic interactions, dealing especially with cross innervation studies. Other workers discussed experiments utilising chronic stimulation of nerve or muscle both in animals and man to alter the histochemical, biochemical and physiological characteristics of muscle.

In a session on myasthenia gravis Dr E. Heilbronn (Stockholm) described the production of experimental myasthenia gravis in rabbits immunised with a purified preparation of acetylcholine receptor from the electric organ of Torpedo, and the effect of antibodies against this receptor. This will probably prove a fruitful model for the investigation of abnormalities of neuromuscular transmission. Various other immunological aspects of myasthenia gravis were considered, including the significance of HL-A antigens and various skeletal muscle and other antibodies. Dr G. H. Oosterhuis (Amsterdam) reported no correlation between thymic histology and the prognosis for myasthenia gravis.

A session was devoted to the neural theory of muscular dystrophy. Several workers, including Drs C. P. Panayiotopoulos (Athens National University), J. P. Ballantyne (University of Glasgow) and Professor W. G. Bradley (University of Newcastle upon Tyne) questioned the evidence upon which the theory was originally based. They considered both technical aspects and questions of logic; Professor A. J. McComas (McMaster University) defended the theory. Both Panayiotopoulos and Ballantyne reported studies using different techniques of motor unit counting in human muscle, finding no fall in the number of motor units in dystrophic patients compared with their own controls. The estimated number by their two different techniques was however not identical. Bradley reported that changes in the nerves of mice with muscular dystrophy were not found in 